\title{
The Effects of ICT and Longhand Note-taking on Students' Comprehension
}

\author{
Clara Herlina Karjo \\ Bina Nusantara University \\ claraherlina@yahoo.com
}

\begin{abstract}
With the advent of technology nowadays, taking notes by hand seems old-fashioned to most students nowadays. Typing on ICT devices (such as laptops, smartphones, and tablets), on the other hand, is preferable since it is more practical and can record more information. Note-taking (either by hand or using gadgets) is a powerful and inevitable way of learning. However, each mode of note-taking will have a different effect on students' understanding of course materials. A study by Mueller \& Oppenheimer (2014) found that students who took notes by hand performed better in their learning and retention compared to those who took notes using ICT devices. The purpose of the present study was to find out whether note-taking using ICT devices affect the students' comprehension of the lecture. This study used a quasi-experimental design, with 50 English department students of Bina Nusantara University as the participants. They were divided into two groups as the control and experimental group. Participants of both groups were shown various videos from TED talks, with topics related to their majors. While watching the videos, the control group was instructed to take notes by hand, while the other group took notes using their various devices. After that, participants had to do the test regarding their comprehension of the lecture videos. The results revealed that students who made notes using handwriting performed better in comprehension test than students who made notes using their ICT devices. The findings implied that the traditional pen and paper note-taking is more effective than ICT devices in improving learning and understanding.
\end{abstract}

Keywords: note-taking, ICT, gadgets, lecture videos, longhand, TED talks

\section{INTRODUCTION}

In an academic environment, note taking is a powerful and inevitable way of learning. Patterson et al. (1992) classify note taking as an organizing and focusing strategy. Notes help students to remember the important points of a lesson, and to be used for revision and reference purposes. According to Arslan (2006), note taking has three benefits. First, it increases attention to the lesson. Second, it aids memory for the lesson, and third, it produces a set of notes available for review.

There are two ways in which note taking can affect learning: encoding and external storage (Kiewra, 1989). The encoding hypothesis suggests that the processing that occurs during the act of note taking improves learning and retention. The external storage hypothesis pushes the benefits of the ability to review material (even from the notes taken by someone else). Quade (1996) also says that students take notes because of both the encoding and storage functions, to maintain written records of what occurs in the text and later use this record to enhance review.

Note-taking can be done longhand, i.e. with traditional paper and a pen or by using gadgets (computers, laptops, or even cell phones). However, due to the advance of technology (and maybe students' idleness), more and more students do not bring their paper and pen to class. Instead, they use their gadgets to aid their learning in the classroom. While it is impossible to defy this trend, many experts still believe that computers (and the Internet) serve as distractions, detracting from class discussion and students' learning (Yamamoto, 2007).

Therefore, to incite students' awareness to 'go back to basic' of learning, the writer is conducting a quasiexperimental study to compare the comprehension results of students who take notes using pen and paper and those who takes notes using their gadgets. This study has two objectives. One objective is to compare taking notes by hand with taking notes using gadgets of their effects on comprehension test performance. The second objective is to find out which types of test items are better performed by each group.

Previous studies such as Mueller and Oppenheimer (2014) reported that participants who had taken notes with laptops performed worse on tests of both factual content and conceptual understanding, relative to participants who had taken notes longhand. Similarly, Steimle, Gurevych, and Mühlhäuser (2007) also stated that taking notes with a pen and paper is considered easier and faster. Therefore, the vast majority of students prefer longhand note-taking than using a laptop. Conversely, Bui et al. (2013) say that when people used a computer to take notes, they took more notes and recalled more of the lecture than when they took notes by hand.

\section{METHODS}

Research design: This is a quasi-experimental study using the posttest-only control group design (Creswell, 2009) in order to measure participants' performances in comprehension test after being instructed to take notes using longhand or gadgets.

Participants: The participants for this study were 50 English Department students of Bina Nusantara University. At the time of the study, they were in the sixth semester taking Research Method subject. They participated in this study as part of course requirements.

Material: The material for this study was one video from TED Talks (https://www.ted.com/talks) entitled "The Process of Writing Literary Review." The video duration was around 15 minutes. TED (Technology, Entertainment, Design) is a global set of conferences run by the private non-profit 
Sapling Foundation, under the slogan "Ideas Worth Spreading." The emphasis is on the educational aspect.

Data Collection Procedure: Prior to the experimentation, the students were divided into two groups, longhand group, and ICT group. During the experiment, both groups were instructed to watch the same video twice. While they were watching the video, they were instructed to take notes according to their group assignment. The longhand group was assigned to make notes using pen and paper, while the other group was assigned to take notes using their ICT devices (cell phones, tablets, IPAD, or laptops). After watching the video and taking notes, they were given some time to review their notes. Finally, all the participants from the two groups were given the same test regarding the materials they had learned from the video. Students were allowed to consult their notes while doing their tests.

Data Analysis: The participants' test papers consisted of five parts, namely: completion, definition, summarizing, making a diagram and word listing. Each part contains five items, so the total is 25 items. Each participant's test paper was given a total score and scores for each part. All the participants' total scores were processed using SPSS program to obtain the mean score and significant value to determine which note-taking medium give the better result.

\subsection{Results of Longhand versus ICT devices note-taking}

Table 1: Group Statistics

\begin{tabular}{|c|c|c|c|c|c|}
\hline & group & $\mathrm{N}$ & Mean & $\begin{array}{l}\text { Std. } \\
\text { Deviation }\end{array}$ & $\begin{array}{l}\text { Std. } \\
\text { Error } \\
\text { Mean }\end{array}$ \\
\hline \multirow{2}{*}{ Value } & Note & 26 & 79.54 & 14.938 & 2.930 \\
\hline & Gadget & 26 & 70.46 & 22.545 & 4.421 \\
\hline
\end{tabular}

Independent sample t-test was used to test differences between the two groups: longhand versus gadget. The table shows that the longhand group performed better in comprehension test by attaining the mean score of $79.54(S D=14.938)$, while the gadget group only got a mean score $70.46(S D=22.545)$. There is a difference of 9.08 , indicating that participants who took notes using pen and paper retain more information compared to those who took notes using their gadgets. These results provided evidence that using gadgets might not be too effective for academic performance. Participants using gadgets are more likely to type verbatim like notes. Mueller and Oppenheimer (2014) confirmed that even though taking more notes and having more information is beneficial for learning, mindless transcription will offset its benefit. The above findings are strengthened by the significance value obtained for the comparison of means.

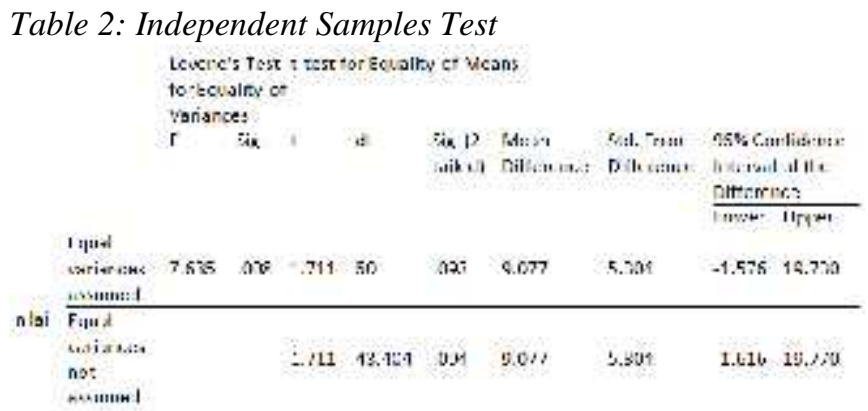

From the above SPSS results, the assumption that both variances are equal is fulfilled based on the hypothesis: $H O: \sigma l$ $=\sigma 2$ (in which $\sigma 1=$ variance of ALT group and $\sigma 2=$ variance of VLT group). This is because the $\boldsymbol{p}$-value $=0.008$ which is smaller than $\alpha=0.05$ for equal variance assumed, thus $H 0$ : $\sigma l$ $=\sigma 2$ is rejected. In other words, the equal variances assumed are not fulfilled, then we should use equal variances not assumed. Because the Levene's Test of equal variances is not assumed, the result of independent sample t-test for hypothesis HO: $\quad 1=2$ gives a $\mathrm{t}=1.711$ with the degree of freedom 43.404 and $\boldsymbol{p}$-value $(2$-tailed) $=0.094$. Because the test is done for the one-tailed hypothesis, then p-value should be divided by 2 become $0.094 / 2=0.047$ which is smaller than $\alpha=0.05$, then HO: $1<2$ is rejected. Then, it can be concluded that students who take notes with pen and paper perform better in comprehension test. The findings corroborate Kiewra's (1989) view that note-taking improves learning and retention, particularly if the note-taking is done using pen and paper.

\subsection{The effects of note-taking medium on question types}

\begin{tabular}{|c|c|c|c|c|}
\hline Ined tiplem & 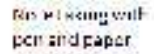 & 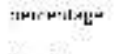 & 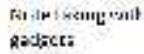 & $\|+1-1 x_{0}-$ \\
\hline temslstier & 3.41 & $\mathrm{~N}<3$ & $2 . ;$ & $5.1 x$ \\
\hline Drfinul A.? & :I.su & $1 \mathrm{~s}^{2}$. & . 1.131 & $x \rightarrow+\infty ;$ \\
\hline f.tmuratin &. .11 & 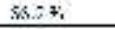 & 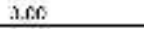 & $6 \%$ \\
\hline 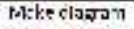 & 4.65 & $358 \%$ & 4.54 & א.\&\$ \\
\hline Letet werds & 1.2. & $\forall j ;$ & 3,27 & $31, \mathrm{~s}$ \\
\hline
\end{tabular}

Kiewra (1985) mentions that note taking can be generative (e.g. summarizing, paraphrasing, concept mapping) or nongenerative (i.e. verbatim copying). Relating to the types of notes, the devices used for making notes will also influence the kinds of notes produced. For example, verbatim copying was easier done using computer, or laptop. Olive and Piolat (2002) mentioned that when people used a computer to take notes, they recalled more of the lecture. Brown (1988) also said that laptop use facilitates verbatim transcription of lecture content because most students can type significantly faster than they can write. However, other devices such as IPAD, tablet or cell phone do not give similar facility in typing a large amount of information. One student said that it is extremely difficult to type fast using a cell phone. On the other hand, when students make notes using pen and paper, they should select the most important information before putting it into notes. This is because they cannot write verbatim everything they hear. Using pen also enables them to draw concept mapping or 
making diagram. Even in its simplest form, the diagram can be made faster on paper, rather than on a computer.

The above considerations are reflected in the results of their comprehension test. Only for one type of test, writing a definition, the gadget group excels over the longhand group. This may be due to their ability to record more words using their gadgets. On the contrary, for the other types of test, especially in completing and making a diagram, the pen and paper group performed better. The same goes for the other two types of test, summarizing and recalling lists of words. Students who make notes with their handwriting have previously summarized and selected the information in their notes.

\section{CONCLUSION}

ICT devices or gadgets are increasingly used in the classrooms as teaching learning aids. However, in a case of making notes for studying and reviewing, the traditional pen and paper seem irreplaceable with gadgets. This study has confirmed numerous other studies that taking notes with handwriting can give better results in students' comprehension of a lecture. Regarding the type of test, students who take notes with handwriting seem to excel in every type, except in giving definition.

This study, however, does not measure the retention or recall performance of the students, because the students were allowed to do the test by consulting their notes. For the next study, the participants should be allowed to review their notes, but not allowed to consult their notes during the test, to measure participants' retention of information.

\section{REFERENCES}

Arslan, M. (2006). The influence of teaching note-taking and information mapping on learning and recalling in science. TOJET: The Turkish Online Journal of Educational Technology, 5(2), 1-8.

Bui, D. C., Myerson, J., \& Hale, S. (2013). Note-taking with computers: Exploring alternative strategies for improved recall. Journal of Educational Psychology, 105(2), 299 310.

Brown, C. M. (1988). Comparison of typing and handwriting in "two-finger typists." Proceedings of the Human Factors Society, 32, 381-385.

Creswell, J.W. (2009). Research design. Los Angeles: Sage Publication

Kiewra, K. A. (1985). Investigating notetaking and review: A depth of processing alternative. Educational Psychologist, 20(1), 23-32.

Kiewra, K. A. (1989). A review of note-taking: The encodingstorage paradigm and beyond. Educational Psychology Review, 1(2), 147-172.

Mueller, P. A., \& Oppenheimer, D. M. (2014). The pen is mightier than the keyboard; advantages of longhand over laptop note taking. Psychological science, 1-10

Olive, T., \& Piolat, A. (2002). Suppressing visual feedback in written composition: Effects on processing demands and coordination of the writing processes. International Journal of Psychology, 37, 209-218.

Patterson, M, E., Dansereau, D. F., \& Newbern, D. N. (1992). Effect of communication aids on strategies on cooperative teaching. Journal of Educational Psychology, 84(4), 453-461.

Quade, A. M. (1996). An assessment of retention and depth of processing associated with notetaking using traditional pencil and paper and an on-line notepad during computerdelivered instruction. In M. R. Simonson, M. Hays, \& S. Hall (Eds.), Proceedings of selected research and development presentations at the 1996 convention of the association for educational communication and technology, 559-570

Steimle, J., Gurevych, I., \& Mühlhäuser, M. (2007). Notetaking in university courses and its implications for elearning systems. In DeLFI ,5, 45-56.

Yamamoto, K. (2007). Banning laptops in the classroom: Is it worth the hassle? Journal of Legal Education, 57, 477520 